\title{
Transport Phenomena in Paper and Wood-based Panels Production
}

\author{
Helena Aguilar Ribeiro', Luisa Carvalho', ${ }^{1,2}$ \\ Jorge Martins ${ }^{1,2}$ and Carlos Costa ${ }^{1}$ \\ ${ }^{1}$ Universidade do Porto - Faculdade de Engenharia, \\ Laboratory for Process, Environmental and Energy Engineering, \\ 2Instituto Politécnico de Viseu, Wood Engineering Department, \\ Portugal
}

\section{Introduction}

\subsection{A brief historical perspective of paper and wood-based materials}

The pulp and paper industry is a vital manufacturing sector that meets the demands of individuals and society. Paper is an essential part of our culture and daily lives, as it is used to store and share information, for packaging goods, personal identification, among other end uses. In an age of computers and electronic communication, paper is still envisaged as one of the most convenient and durable option of data storage, and a material of excellence for artists and writers. It is not surprising that the birth of modern paper and printing industry is commonly marked from the increasing demand for books and important documents in the $15^{\text {th }}$ century. In 2008 the Confederation of European Paper Industries (CEPI) reported a global world paper production of 390.9 million tonnes covering a wide range of graphic paper grades, household and sanitary, packaging and other carton board grades (CEPI, 2010). The CEPI member countries account for $25.3 \%$ of the world paper and board production, slightly above North America (24.5\%) but far behind Asia (40.2\%). In volume terms, graphic paper grades account for $48 \%$ of the Western European paper production, packaging paper grades for some $41 \%$, and hygiene and utility papers for $11 \%$ (CEPI, 2010). Additionally, forecasts indicate that from 1998 to 2015 there will be an increase of $2.8 \%$ in the consumption of paper and board globally. It is clear, therefore, that despite the growth of alternatives to paper like electronic media, several paper grades will still play an important role in our lives. Moreover, other materials used in a day-to-day basis derive from wood fibres extracted from a diversity of arboraceous species. As an example, "woodbased panels" (WBP) - a general term for a variety of different board products which have an impressive range of engineering properties (Thoemen, 2010) - are used in a wide range of applications, from non-structural to structural applications, outdoor and indoor, mostly in construction and furniture, but also in decoration and packaging. The large-scale industrial production of wood composites started with the plywood industry in the late $19^{\text {th }}$ century. A number of new types of wood based panels have been introduced since that time as hardboard, particleboard, Medium Density Fibreboard (MDF), Oriented Strand Board (OSB), LVL-Laminated Veneer Lumber and more recently LDF (Light MDF) and HDF (High Density Fibreboard). The production of wood-based panels is still an important part of the 
world's total volume of wood production. In 2009, FAO (Food and Agriculture Organization of the United Nations) reported that a total of 255 million $\mathrm{m}^{3}$ was produced in the world (Europe 29.7\%, Asia 43.9\%, North America 18.3\% and others 2.5\%). In case of MDF the production in Europe was 19.1 million $\mathrm{m}^{3}$ (Wood Based Panels International, 2010).

\subsection{Research and development in a high-tech industry: major advances and concerns}

Research, development and innovation are the key to many of the challenges paper and wood-based materials industry are facing today. In the last decades, substantial development work has been undertaken to improve the pulp and paper qualities of today, taking into account features such as printability, press runnability, sheet opacity/low grammage and barrier properties. Modern paper machines are giant tailor-made units that carry out the two major steps of papermaking: dewatering and consolidation of a wet paper web made of cellulose fibres, chemical additives and water. In fact, the production of paper is mainly a question of removing as much water as possible from the pulp at the lowest possible cost. During papermaking, water removal takes place in three stages, namely in the wire, press and drying sections of the paper machine. In the first stage, water content is reduced from $99 \%$ down to about $80 \%$ using gravitational force or with the aid of suction boxes. In the press section, the dewatering process continues by mechanical pressure, increasing the paper web dryness to about $35-50 \%$. The paper then enters the drying section, which is comprised of several rotating heated cylinders, and most of the remaining water is evaporated from the paper. At this stage, the dryness of the web has increased up to about $90-95 \%$. Even though the water removal in the drying section is relatively modest, this is by far the most energy demanding stage of the web consolidation process, making mechanical dewatering a much more cost-effective process than evaporation. Also, the demand for higher productivity led to a significant increase in the speed of the paper machine, which in its turn results in higher water content after the press section, thus increasing the effort put in the dryer section. As a result, a considerable emphasis has been given over the last thirty years, by researchers and paper makers, to the development of more efficient press sections. In the 80's, a new concept arised with the development of the so-called extended nip presses, which includes the terms high impulse presses, long-nip presses, wide-nip presses and shoe presses, the common feature to all being the increased contact time between the paper web and the pressing element, thus leading to a significant higher dryness (Pikulik, 1999). In some emerging techniques such as press drying, the Condebelt process and more recently impulse drying, higher levels of dryness are possible. Moreover, the implementation of these methods showed to significantly reduce the dimensions of the paper machine dryer section and the use of steam while allowing to obtain a drier and stronger sheet at the end of the press section. In summary, the overall-aim of developments in the press section has been to improve the energy efficiency of web consolidation and paper properties.

Similar technological advances have been undertaken in the field of wood-based panels, which are produced from particles (as particleboard or OSB), fibres (as MDF, softboard or hardboard) or veneers (as plywood or LVL), using a thermosetting resin, through a hot pressing process. The hot-pressing operation is the final stage of its manufacturing process, where fibres/particles are compressed and heated to promote the cure of the resin. This operation is the most important and costly in the manufacture of wood-based panels. In the last decade, the technology for the production of wood-based panels had an important change in response to ever changing markets. The international research in this field is driven by improvements in quality (better resistance against moisture and better mechanical resistance) and cost reduction 
by energy savings (shorter pressing times) as well as the use of more cost effective raw materials (cheaper and alternative raw materials, reuse and recycling) (Carvalho, 2008). Environmental regulations and legislation regarding VOCs (volatile organic compounds) emissions, in particular formaldehyde, are important driving forces for technological progresses. Although panel product emissions have been dramatically reduced over the last decades, the recent reclassification of formaldehyde by IARC (International Agency for Research and Cancer) as "carcinogenic to humans", is forcing panels manufacturers, adhesive suppliers and researchers to develop systems that lead to a decrease in its emissions to levels as low as those present in natural wood (Athanassiadou et al., 2007).

\section{Heat and mass transfer phenomena in porous media}

\subsection{Introduction}

Many problems in scientific and industrial fields as diverse as petroleum engineering, agricultural, chemical, textiles, biomedical and soil mechanics, involve multiphase flow and displacement processes in a heterogeneous porous medium. These processes are mainly controlled by the pore space morphology, the interplay between the viscous and capillary forces, and the contact angles of the fluids with the surface of the pores. Estimating the capillary pressure and relative fluid permeabilities across the porous media can therefore be very complex, especially if the medium is deformable as is the case of paper and woodbased panels. In fact, the most important process in paper production is dewatering of the cellulose fibre suspension, which has a concentration less than $1 \%$ entering the forming section of the paper machine. In particular, the wet pressing of paper - or other wood based materials - may be envisaged as the simultaneous flow of two fluids, water and a mixture of air and water vapour, in a deformable porous medium. The following sections address the drying processes of paper and MDF, with special emphasis in the dewatering and consolidation mechanisms involved in the press section. Here, a deep knowledge of the interactions between heat and water is of utmost importance to control and optimize this operation in order to improve paper/MDF quality and to reduce the operational costs. The development of theoretical models based on the many physical, chemical and mechanical phenomena that are involved in this operation, constitutes an attempt to understand and quantify the most diverse interacting transfer mechanisms (simultaneous heat and mass transfer with phase change, and the rheological behaviour of the fibrous material).

\subsection{Foundations of flow analysis in compressible porous media 2.2.1 Consolidation mechanisms involved}

As previously mentioned, the production of paper and wood-based materials, such as MDF, is mainly a question of consolidation of the fibrous network by removing as much water or gas (air + water vapour) as possible from the interstitial void space. For instance, in the pressing process in a roll press, the paper web is squeezed together with one or more press felts between two rolls exerting a mechanical pressure on both materials (Fig. 1). During the compression phase water will flow from the paper web into the felt forced by a positive hydraulic pressure gradient. At the end of the press nip, when load is being released, the hydraulic pressure gradient will become negative, which may result in some rewetting caused by the back-flow of water and air from the felt to the paper web. Furthermore, if applying a heated press roll an energy flow from the roll to the paper web will be established at the moment the web makes contact with the press roll. Depending on the 
temperature and pressure conditions imposed to the paper web/felt sandwich steam may be generated inside the paper web and ultimately induce web delamination, which occurs when the force dissipated by the flow of steam generated inside the paper web is larger than its z-directional strength (Larsson et al., 1998; Orloff et al., 1998). It has been shown, however, that proper temperature/pressure control in the press nip may prevent steam generation inside the paper web. Moreover, the ability of pulp fibres to form fibre-to-fibre bonds during the consolidation process is an important characteristic, which strongly influences the structural and mechanical properties of paper and wood-based materials in general. It depends mainly on wood species, and/or pulping method, fines content, amount of bonding agents (additives, resins), chemical modification of fibres, refining and ultimately on the pressing conditions (Skowronski, 1987). In fact, when high temperature pressing conditions are employed, fibre flexibility and conformability are improved, which may explain the higher sheet densification levels observed under such intense operating conditions.

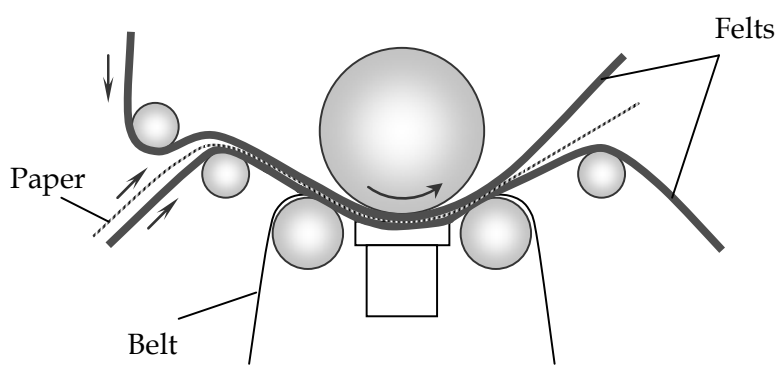

Fig. 1. Press nip of a shoe pressing machine (Aguilar Ribeiro, 2006).

The thermal softening of the fibre's cell wall material is thus partially responsible for the increased mat consolidation and sheet density, but it also induces a significant drop in air and water permeability as the fibrous material dries and consolidates. Since the flow of water and air encounters different cumulative flow resistances across the thickness of the web, the final density profiles may show some signs of stratification, e.g. nonuniform z-direction density profiles. This is influenced by several factors such as the permeability of the pressing head contacting the fibrous material, the temperature/pressure conditions of the pressing event, the web moisture content and fibre's properties, and the uniformity of pressure application.

\subsubsection{Hydraulic and structural pressures generated during compression of a wet web: factors affecting the governing mechanisms of water removal}

According to Szikla, the role of various factors in dynamic compression of paper is greatly influenced by the moisture ratio of the web, suggesting different governing mechanisms over different ranges of moisture ratio and/or density (Szikla, 1992). In order to remove water by compaction from a web, the mechanical stiffness of the structure must be overcome and water must be transported. The mechanical stiffness of a fibrous mat is influenced by its moisture content, reaches its maximum when all the water has been removed from the web, and decreases continuously as the moisture content increases. Therefore, the pressure carried by the mechanical stiffness of a saturated web during the compression phase of a pressing event cannot be higher than the pressure measured at the same density when an 
unsaturated web is pressed. The two values may be close to each other as long as significant water transport does not take place in the unsaturated web. The experimental results obtained by Szikla (1992) for 50 g.m-2 paper sheets of mechanical or chemical pulps under dynamic load and ingoing moisture ratios in the range $2.0-4.0 \mathrm{~kg} \mathrm{H}_{2} \mathrm{O} / \mathrm{kg}$ dry fibres, showed that an increase in chemical pulp beating resulted in higher contribution from hydraulic pressure; an increase in fibre's stiffness, the removal of fines and a decrease in compression rate all lowered the hydraulic pressure. His results also showed that flow in the inter-fibre voids plays an important role in the dynamic compression behaviour of wet fibre mats. When the moisture ratio of the web is high and the compression is fast, as in paper machines, most of the compression force is balanced by the hydraulic pressure that builds up in the layers of the web close to the impermeable pressing surface. This is the case for low grammage paper (e.g. 40-50 g.m-2). The role of hydraulic pressure in balancing the compression force decreases as the compaction of the web increases.

Regarding the mechanisms of dynamic compression of wet fibre mats, the following conclusions can be drawn from the work of Szikla (1992):

- The mechanical stiffness of the structure must be overcome and water must be transported in order to bring about compression of a wet fibre mat. According to this, the force balance prevailing in pressing can be written in the following form:

$$
P_{t}=P_{\text {mec }}+P_{\text {flow }}
$$

where $P_{t}$ is the total compressing pressure, $P_{\text {mec }}$ the pressure carried by the mechanical stiffness of the mat, and $P_{\text {flow }}$ the pressure required to transport water;

- The load applied to a wet fibre mat is carried partly by the structure and partly by the water in the interstices of the structure. The structure is formed by fibre material and water. Water located in the lumen of the fibre wall and bound to external surfaces is an integral part of the structure. The pressure carried by the structure is often called structural pressure, $P_{s t}$, and the load carried by the water hydraulic pressure, $P_{h}$. The pressure carried by the mechanical stiffness of a fibre mat constitutes only a part of the structural pressure. Another part of the structural pressure is a result of water transport within the fibre material. According to this classification, the force balance can be written in the following form:

$$
P_{t}=P_{s t}+P_{h}=\left(P_{m e c}+P_{f h}\right)+P_{h}
$$

where $P_{f h}$ is the structural pressure due to water transport within the fibre material. The structural pressure is equal to the pressure carried by the mechanical stiffness of the fibre material only when water transport within the fibre material is negligible. On the other hand, in most paper sheets there are large density ranges over which the pressure generated by the water transport within the fibre material plays a dominant role in forming the structural pressure.

Quantitatively, Terzaghi's principle has to be used carefully in the case of highly deformable pulp fibre networks, as it applies rigorously only to solid undeformable particles with pointlike contact points. In a deformable porous material the hydraulic pressure is only effective on a share (1-a) of the area A (Fig. 2). So being, the stress balance may be written as:

$$
P_{t} A=P_{s t} A+P_{h} A(1-\alpha) \Leftrightarrow P_{t}=P_{s t}+P_{h}(1-\alpha)
$$




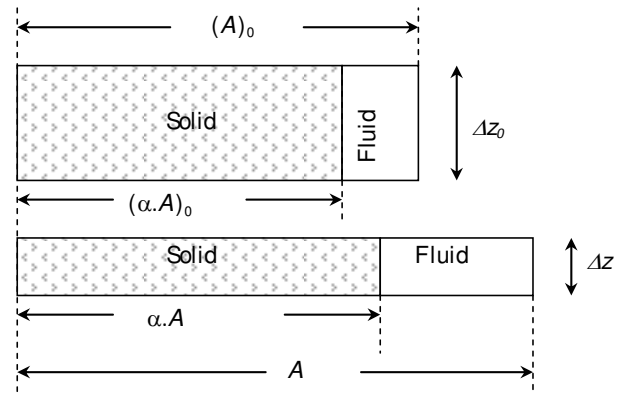

Fig. 2. Schematic diagram of the compression of a deformable porous medium $\left(\Delta z_{0}\right.$ and $\Delta z$ are the initial and final thickness of the fibrous material, respectively).

In conclusion, the dynamic compressing force is balanced in the paper web by the following factors: (i) the flow resistance in the inter-fibre channels; (ii) the flow resistance within the fibres (intra-fibre water); (iii) and the mechanical stiffness of the fibre material.

\subsection{Fundamentals of wet pressing and high-intensity drying processes: simultaneous heat and mass transfer \\ 2.3.1 Wet pressing}

It is convenient to think of wet pressing as a one-dimensional volume reduction process, with the fibrous matrix and water assumed to be a more or less homogeneous continuum. However, when visualized in the microscope (Fig. 3), wet pressing is a far more complex process which combines important mechanical changes in the fibre network with threedimensional, highly unsteady, two-phase flow through a rapidly collapsing interconnected porous network.

In wet pressing, volume reduction, fluid flow, and static water pressure gradients are intimately interrelated. Classical Fluid Mechanics states that the static water pressure is reduced in the direction of flow by conversion into kinetic energy (water velocity). Some of the total energy available at each layer is lost to friction with the surrounding fibre and by microturbulence in the narrowing flow paths. This loss is associated with fluid shear stresses. However, the water-filled fibre network should not really be considered a continuous confined system (e.g. water flowing in a pipe).

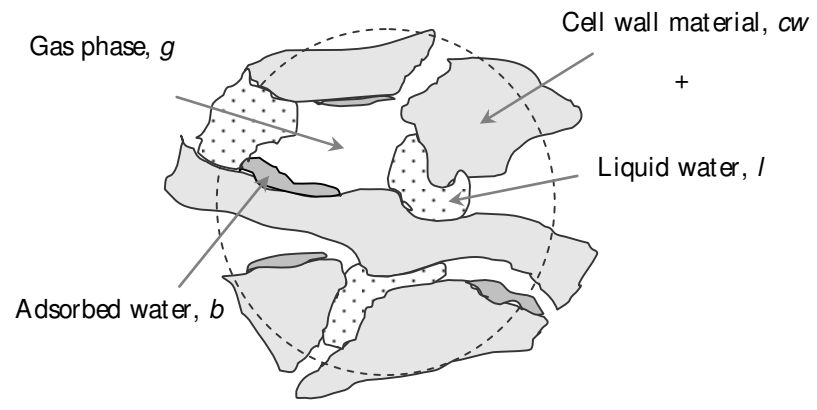

Fig. 3. Micro-scale constituents of paper and MDF (in this case free liquid water should not be considered) (Aguilar Ribeiro, 2006). 
The local velocity vector changes direction frequently as the water is forced to take a tortuous path across the collapsing fibre network. Despite the simplifications offered by classical fluid mechanics, it seems safe to say that the static water pressure is highest at the smooth roll surface (if referred to a roll press of a paper machine - or in a lab-scale platen press, as shown in Fig. 4), where water is not in motion relative to the fibres, and lowest at the felted side of the paper, where water velocity is highest. In a roll press the largest static water pressure gradient is not directly downward - it is oriented slightly upstream and, coupled with a significantly higher in-plane sheet permeability, must create some longitudinal water flow component towards the nip entrance.

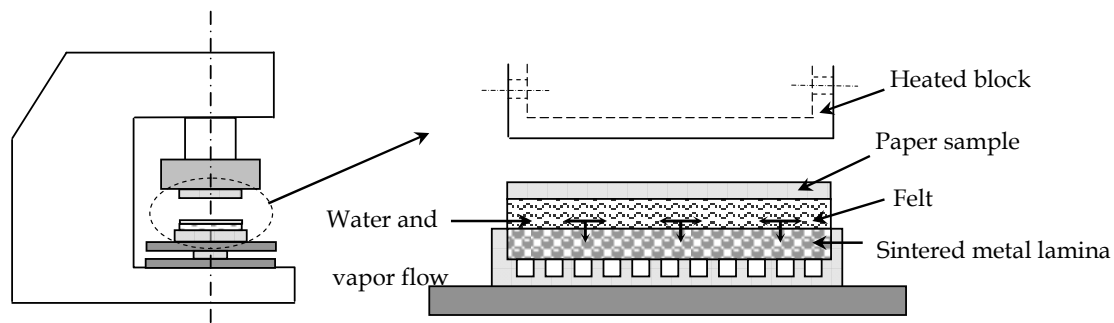

Fig. 4. Schematic drawing of a lab-scale platen press for paper consolidation experiments. The inset shows the water flow pattern and the paper/felt sample arrangement within the press nip (Aguilar Ribeiro, 2006).

Wahlström showed that water is removed from the paper web in the converging part of the press nip due to web compression, but that part of the expressed water returns into the web on the outgoing side of the nip due to capillary forces (Wahlström, 1960). Another important pillar of wet pressing theories has been the division of the total applied load into hydraulic and structural components. The sum of the two pressure components has been considered to be constant in the z-direction and equal to the total applied pressure in the pressing machine but the contribution of these components is considered to change in that, progressing in the direction of water flow hydraulic pressure decreases and structural pressure increases. This idea of separating the two components of pressure, originating from Terzaghi (1943), was applied to the compression behaviour of paper webs by Campbell (1947). Later on, Carlsson's and his co-workers' studies (Carlsson et al., 1977) revealed the important role of water held within fibres in wet pressing, showing that water present in the intra-fibre voids must make a significant contribution to the structural pressure. Only the water in the inter-fibre voids is responsible for the hydraulic pressure. The rest of the structural pressure is the result of mechanical stiffness.

However, it was gradually realized that the original definition of hydraulic and structural pressures was oversimplified. Classical wet pressing theory separates the total applied pressure into only two components - static water pressure and the network compressive stress (usually called mechanical pressure). The stress associated with the fluid drag force here called fluid shear stress - and the static water pressure drop always appear together; one cannot exist without the other. The vertical component of fluid shear stress should be added to the fibre network stress to obtain the total compressive stress acting at each layer of the fibrous web. Fluid stress is maximum at the outflow side of the paper and nonexistent at the smooth press roll side. It is also nonexistent after the point of zero hydrodynamic pressure since water flow has ceased. Fluid shear stress also has an in-plane component 
which must be taken into account when considering paper properties. Although the value of Terzaghi's principle as a tool for quantitative predictions has been questioned by Kataja et al. (1995), it still constitutes the basis of our understanding of wet pressing. Consequently, the operations of press nips are traditionally divided into two categories. In the first case, the press nip is considered to be compression-controlled. Here, the mechanical stress in the fibre network is the dominating factor, and the maximum web dryness is determined by the applied pressure, and is independent of the pressing time. On the other hand, the nip is considered to be flow-controlled when the viscous resistance between water and fibres controls the amount of dewatering. Here, web dryness increases with the residence time at the nip, and the fluid flow is proportional to the pressure impulse which is the product of pressure and time. Schiel's work (1969) led to the conclusion that for many cases the problem was not in applying enough press load (this wouldn't bring much dryness improvement), but in applying enough pressing time. Wahlström also coined the well known terms "pressure-controlled" and "flow-controlled" pressing as a way to denote whether the water removal was restricted by fibre compression response or by fluid flow resistance inside the paper sheet (Fig. 5). It was then concluded that the moisture content of a wet sheet leaving a press nip depends both on the compressibility of the solid fibrous skeleton and on the resistance to flow in the porous space (Wahlström, 1960).

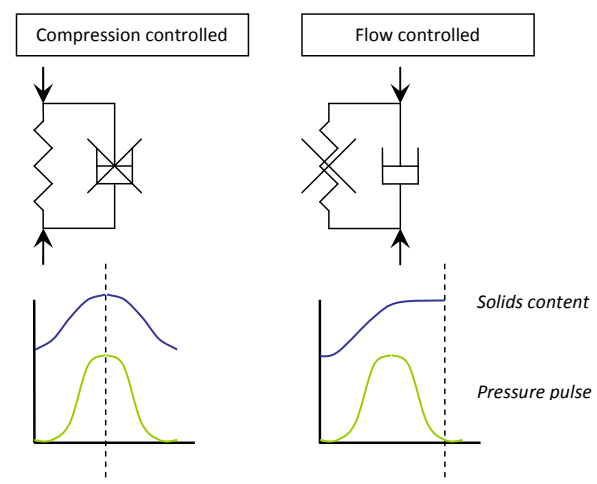

Fig. 5. Schematic drawing of compression-controlled and flow-controlled press nips for an applied roll-like pressure profile on a paper machine (adapted from Carlsson et al., 1982; Aguilar Ribeiro, 2006).

As a consequence of the applicability of Terzaghi's principle to flow-controlled press nips, the web layers closer to the felt in a paper machine are compacted first, with the higher density at the sheet-felt interface. MacGregor (1983) described this phenomenon as stratification and its existence has been observed in laboratory experiments (Burns et al., 1990; Szikla and Paulapuro, 1989a, 1989b; Szikla, 1992). Yet, a recent study performed by Lucisano shows opposing evidence to the existence of a density profile as it was previously reported by several authors. When trying to characterize the delamination process by the changes in transverse permeability and solidity profiles he found no evidence that wet pressing, and even impulse pressing (see section 2.3.3), induced stratification in nondelaminated sheets and concluded that the parabolic solidity profiles observed were due to capillary forces present during oven drying and not a result of hydrodynamic forces induced onto the fibres during the pressing event (Lucisano, 2002). 


\subsubsection{Batch and continuous hot pressing of medium-density fiberboard (MDF)}

MDF, as other wood-based panels, can be manufactured using batch (single or multidaylight) or continuous presses. Steam injection, platen and/or radio-frequency or micro-waves can be used as heating systems. The most common type is the batch press with heated plates (multidaylight), but in the last decade batch presses are being substituted by continuous presses with moving belts. Continuous presses have heating zones along their length and are more efficient than batch presses for thin MDF, allowing to attain line speeds of $120 \mathrm{~m} / \mathrm{min}$ (Irle \& Barbu, 2010).

The consolidation of MDF panels is therefore achieved through hot-pressing. The thermal energy is used to promote the cure of the thermosetting adhesive and soften the wood elements, and the mechanical compression is needed to increase the area of contact between the wood elements to allow the possibility of adhesive bond formation. The hot-pressing process should be regarded as a process of simultaneous mass and heat transfer. However, other mechanisms are also important as they are tightly coupled with heat and mass transfer: the rheological behaviour and the adhesive polymerisation reaction. The material's rheological behaviour, affected by the development of adhesive bonds among fibres, as resin cures, will determine the formation of a density profile in the thickness direction of the MDF panel. These mechanisms are also dependent on temperature and moisture distributions and have direct influence on heat and mass transfer across the mattress porous structure.

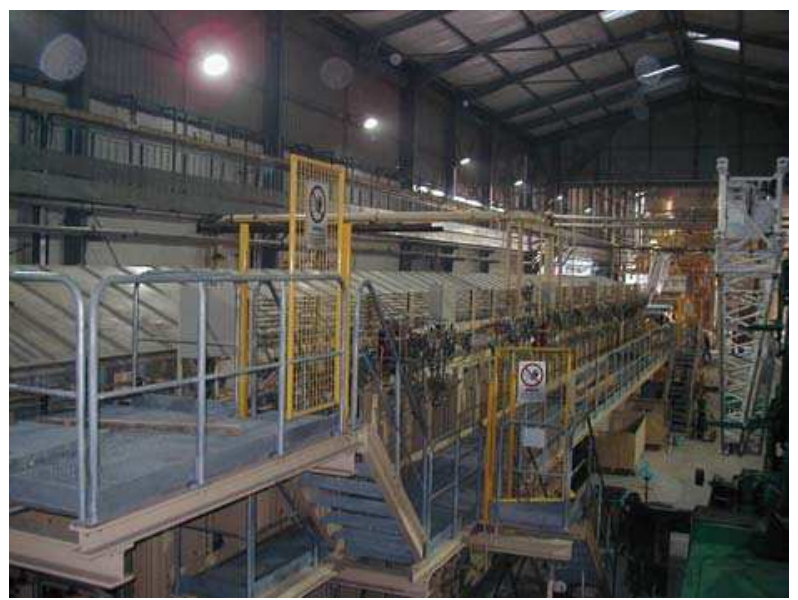

Fig. 6. Continuous press in a particleboard plant (courtesy from Sonae Indústria, Portugal).

In MDF, the mat of fibres forms a capillary porous material in which voids between fibres contain a mixture of air and steam. In addition, liquid water may be adsorbed onto the fibres surface. During the hot-pressing process, heat is transported by conduction from the hot platen to the surface. This leads to a rapid rise in temperature, vaporising the adsorbed water in the surface and thus increasing the total gas pressure. The gradient between the surface and the core results in the flow of heat and vapour towards the core of the mattress, therefore increasing its pressure. As a consequence, a positive pressure differential is established from the interior towards the lateral edges, and then a mixture of steam and air will flow through the edges. So, the most important mechanisms of heat and mass transfer involved are (Pereira et al., 2006): 
i. Heat transfer by conduction due to temperature gradients and by convection due to the bulk flow of gas: conduction follows Fourier's law;

ii. The gaseous phase (air + water vapour) is transferred by convection; each component is transferred by diffusion and convection in the gas phase. Diffusion follows Fick's law and the gas convective flow obeys Darcy's law: the driving force for gas flow is the total pressure gradient, and diffuse flow is driven by the partial pressure gradient of each component;

iii. The migration of water in the adsorbed phase occurs by molecular diffusion due to the chemical potential gradient of water molecules within the adsorbed phase;

iv. phase change of water from the adsorbed to the vapour state and vice-versa.

Heat transfer by conduction: Heat is transferred through the interface plate/mat to the interior by conduction and will be used to resin polymerisation and to remove water present in the mat as bound water. To evaporate this water it is necessary to supply energy equal to the sum of the water latent heat of vaporisation and the heat of wetting (or sorption) sufficient to break hydrogen bonds between water and wood constituents.

Heat transfer by convection: Convection occurs because the heat transferred from the hot platens causes the vaporisation of moisture, increasing the water vapour pressure. A gradient of vapour partial pressure is formed across the board thickness, causing a convective flow of vapour towards the mat centre. On the other hand, the increase of gas pressure will cause a horizontal pressure gradient that will create a flow of heat by convection to the edges. When the temperature of the medium exceeds water ebullition point, imposed by the external pressure, the horizontal pressure gradient becomes the more important driving force (Constant et al., 1996). However, it is not necessary to attain the ebullition point of free water to have a vapour flow. Any change in temperature will affect the EMC (equilibrium moisture content) of wood and so the vapour partial pressure in the voids (Humphrey \& Bolton, 1989). Also, if the vapour is cooled, it will condense, liberating the latent heat and a rapid rise of temperature will occur. So, there is also a phase change associated with the bulk flow, which imparts the temperature change (Kamke, 2004). This condensation will happen continuously from the surface to the core and not as a discrete event, which complicates the modelling of this system.

Heat transfer by radiation: Heat transfer by radiation is usually neglected, since for the relatively lower range of temperatures $\left(<200^{\circ} \mathrm{C}\right)$, it would be insignificant compared with conduction and convection. However, during press closing and before the platen makes contact with the mat, as well as during the first instants of pressing while mat density is relatively low, heat transfer by radiation can be a significant part of the total heat transferred (Humphrey \& Bolton, 1989). On the other hand, on the exposed edges the heat is continuously transported to the surroundings by radiation (Zombori, 2001).

Other heat sources: The other possible sources are the exothermal reaction of the resin cure and the heat of compression. The contribution of the heat of compression is generally neglected. Bowen (1970) estimated that its contribution for heat transfer was around $2 \%$. The contribution of the exothermic polymerisation of the resin depends on the reaction rate and condensation enthalpy.

Mass transfer by convection: In WBP hot-pressing, it is generally assumed that moisture content is below the FSP (fibre saturation point) and so water is present as vapour in cell lumens and voids between particles/fibres, and bound water in cell walls (Kavvouras, 1977; Humphrey, 1982; Carvalho et al., 1998; Carvalho et al., 2003; Zombori, 2001; Thoemen \& Humprey, 2006; Pereira et al., 2006). Two main phases are then considered, the gaseous 
phase (air + water vapour) and the bound water; local thermodynamic equilibrium is also assumed. The gaseous phase is transferred by convection due to a gas pressure gradient (bulk flow) and the water vapour is transferred by diffusion. The bulk flow occurs in response to a gas pressure gradient caused by the vaporisation of moisture present in the mat. Diffusion inside the mat during hot-pressing includes vapour diffusion and bound water diffusion. The driving force for the diffusive flow of vapour is the partial pressure gradient. The convective and diffusive fluxes occur simultaneously, but it is widely accepted that convective gas flow is the predominant mass transfer mechanisms during hot-pressing (Denisov et al., 1975; Thoemen \& Humphrey, 2006).

Mass transfer by diffusion: The migration of water in the adsorbed phase occurs by molecular diffusion and follows Fick's first law with the chemical potential gradient of water molecules within the adsorbed phase as the driving force to diffusive flux. This is a slow process and thus it is often considered negligible by some authors (Carvalho et al., 2003) in comparison with steam diffusion. Zombori and others (2002) studied the relative significance of these mechanisms and they found that the diffusion is negligible during the short time associated to the hot-pressing process. The adsorbed water and steam are then related by a sorption equilibrium isotherm.

Capillary transport: At press entry the moisture content of the furnish is relatively low (generally below 14\%) and although a possible presence of liquid water brought by the adhesive (water content around $50 \%$ ) and capillary condensation in some tiny pores, it is generally assumed that the whole mat is below the FSP (Kavvouras, 1977; Humphrey, 1982; Zombori, 2001; Thoemen \& Humprey; 2006). In case of particleboard, the moisture content at the press entry might be $11 \%$, while the particle moisture content before resin blending could be around $2-4 \%$. During blending, considerable quantities of water are added with the resin (water content around $50 \%$ ), and so unless the equilibrium is achieved by the furnish before entering the press (in that case, the water will be adsorbed in the cell walls of wood) some capillary translation might occur (Humphrey \& Bolton, 1989). In case of MDF, the fibre drying after the resin spraying in the blow-line results in the decrease of moisture and it is reasonable to consider that the equilibrium will be attained before the hot-pressing, and thus the water will be adsorbed in the fibres (Carvalho, 1999). There is also a possibility of capillary condensation in tiny pores. In case of WBPs, the relative humidity does not exceed 90\% (Humphrey, 1984, Kamke and Casey, 1988) and considering a temperature of $115^{\circ} \mathrm{C}$, inside the mat, the maximum pore diameter filled with water will be $0.007 \mu \mathrm{m}$. This will correspond to capillary pressures of 14.6 to $20 \mathrm{kPa}$, which are an order of magnitude less than the predicted maximum vapour pressure differential between the centre and the edges of board (at atmospheric pressure). So, even if some fine capillaries do fill by capillary condensation, it is unlikely that capillary translation of liquid will occur (Carvalho, 1999).

\subsubsection{The concept of impulse drying: application to paper production}

The most obvious goal driving the development of high-intensity pressing and drying techniques is the quest for higher drying rates and more efficient mechanisms of water removal. One such process seems to be impulse drying which combines wet pressing and drying into a single operation. Impulse drying has been postulated to be economically advantageous since it uses less energy than conventional drying because the increased amount of water removed in the improved press section may not need to be evaporated in the dryer section, which now may use less heated cylinders. Designing more compact and shorter paper machines would mean substantial savings in investments. The concept of 
impulse drying was first suggested in a Swedish patent application by Wahren (1978). Instead of conducting heat through thick steel dryer cylinders, heat was transferred rapidly from a hot surface to the paper web using a high pressure pulse. The high heat flow to the paper web generates steam in the vicinity of the paper web surface and the idea was that the formed steam would pass right through the paper web and drag the remaining free liquid water towards a "permeable surface" (the felt) on the other side of the paper web, which would result in extremely high water removal rates and energy efficiencies. According to Arenander and Wahren (1983), this could be explained if the following mechanisms would take place during the pressing/drying event:

i. In the first part of the nip, the wet web is subjected to a compressive load and heat is transferred from the heated surface into the proximate layers of the web. The initial part of the drying event may be considered as a consolidation strategy which enhances dewatering by volume reduction and temperature effects on fibres compressibility and water viscosity;

ii. If the boiling point of water at the actual hydraulic pressure is reached, some steam is generated near the hot surface; steam could only expand towards the felt due to the steam pressure gradient established between the upper and lower surfaces of the paper web; at this moment, the voids in the web are completely or partially filled with water, except for the steam pressurized layers close to the hot surface;

iii. If the steam actually flows through the sheet, it may drag some interstitial water out of the web and into the felt (Fig. 7); moreover, water in the fibres walls and lumens is transferred into the inter-fibre space, becoming accessible to removal either by steam rushing through the web or evaporation.

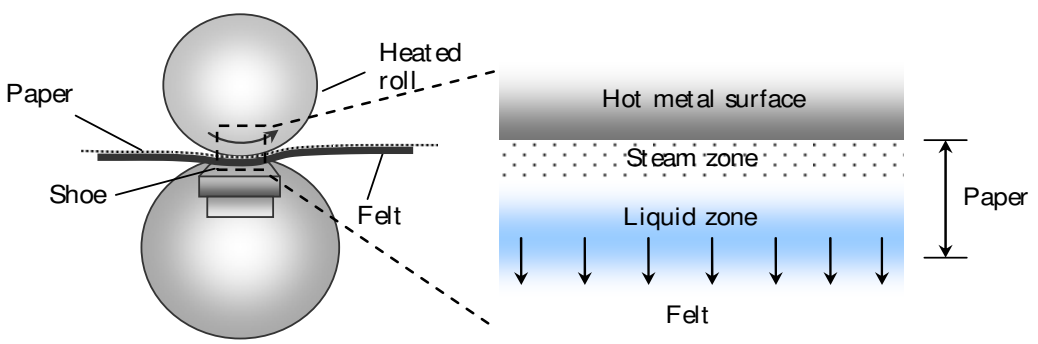

Fig. 7. Design of a shoe press nip. The inset shows a vapour front displacing liquid water in an impulse drying event, as suggested by Arenander and Wahren (1983).

The concept of impulse drying today is somewhat different to Wahren's idea, which consisted in pressing the paper web at a high pressure and high temperature over a short dwell time. Typical operating parameters would be a peak of 2-8 $\mathrm{MPa}$, a temperature of 150$480{ }^{\circ} \mathrm{C}$ and a dwell time of 5-15 ms. Temperatures of $200-350{ }^{\circ} \mathrm{C}$ and lower average pressures are now being used (Metso, 2010). The contact time in the press nip is 15-50 ms depending on the machine speed and the press nip length. A development of impulse drying is to increase the dwell time even further, to super-elongated press nips, to take full advantage of the effects of high pressing temperatures. For effective dewatering and densification of the paper web, it was therefore proposed that impulse drying should be used in the form of a longer nip dwell time or a so-called shoe press (Metso, 2010). In light of this, the heat and mass transfer mechanisms operating in such a complex event will be further addressed throughout the present manuscript. 


\subsubsection{Hot and superhot pressing, evaporative dewatering, steam assisted displacement dewatering: experimental highlights}

The high heat fluxes and water removal rates experienced during the impulse drying event suggest that the mechanisms that control dewatering differ substantially from those of conventional pressing and drying operations. Explanations for such high water removal rates are manifold, but an analysis of the literature published in the field suggests that three modes of water removal can take part in the impulse event:

Hot and superhot pressing, i.e., dewatering by volume reduction, enhanced by temperature effects on network compressibility and water viscosity. The water inside the paper web is considered to be in the liquid state, even if temperature exceeds $100^{\circ} \mathrm{C}$.

Evaporative dewatering, in which thermal energy is used to evaporate water. Here, two modes of liquid-vapour phase change are considered: traditional evaporation or drying, and flashing. Drying refers to the water removal process in which thermal energy is used to overcome the latent heat of evaporation of the liquid phase. Flashing or flash evaporation is another mode of removing liquid water from a solid matrix in which water is exposed to a pressure lower than the saturation pressure at its temperature. In the press nip, water is kept in the liquid state and sensible heat is stored as superheat, which is then converted into latent heat of vaporisation upon nip opening - liquid water is flashed to vapour. The theory of a flash evaporation at the final stage of the impulse drying event was suggested by several authors to explain the dewatering process in impulse drying (Macklem \& Pulkowski, 1988; Larsson et al., 2001).

Steam-assisted displacement dewatering, in which liquid water is displaced by the action of a vapour phase. According to some authors (Arenander \& Wahren, 1983; Devlin, 1986) the resulting steam pressure hypothetically developed in the initial stage of the pressing event is expected to act as the driving force for water removal, displacing the free liquid water from the wet web to the felt (Fig. 7).

The two main opposing theories to explain the high heat fluxes observed in impulse drying - flashing evaporation and steam-assisted displacement dewatering - found experimental evidence in the works developed by Devlin (1986), Lavery (1987), Lindsay and Sprague (1989), and more recently Lucisano (2002) and Aguilar Ribeiro (2006). Lucisano et al. (2001) performed an investigation of steam forming during an impulse drying event by measuring the transient temperature profiles of wet paper webs subjected to a compressive load in a heated platen press. The initial temperature of the platen press was set from 150 to $300{ }^{\circ} \mathrm{C}$ and the length of the applied pressure pulse varied from $100 \mathrm{~ms}$ to $5 \mathrm{~s}$. In light of their findings, they advanced that for faster compression rates - as those used in impulse drying the web stratification induced an increase in the hydraulic pressure which, in its turn, would tend to shift the boiling point of water and prevent steam generation. In summary, the authors believe that for short pulses the hydraulic pressure in most of the sheet is high enough to prevent steam generation and water is present in the liquid phase until the pressure is released. Also, with platen temperatures greater than $200{ }^{\circ} \mathrm{C}$ and nip dwell times shorter than $500 \mathrm{~ms}$, they observed a sudden increase in temperature when pressure was released from the paper samples. The same qualitative trends were observed by Aguilar Ribeiro (2006) when experiments were conducted with more realistic pressing conditions (pressing dwell times reaching down to $75 \mathrm{~ms}$ and pressure profiles resembling more those used in real press machines) - Fig. 8. The results show that platen temperatures below $150^{\circ} \mathrm{C}$ did not induce steam generation as the temperature inside the web remained under $100^{\circ} \mathrm{C}$. 

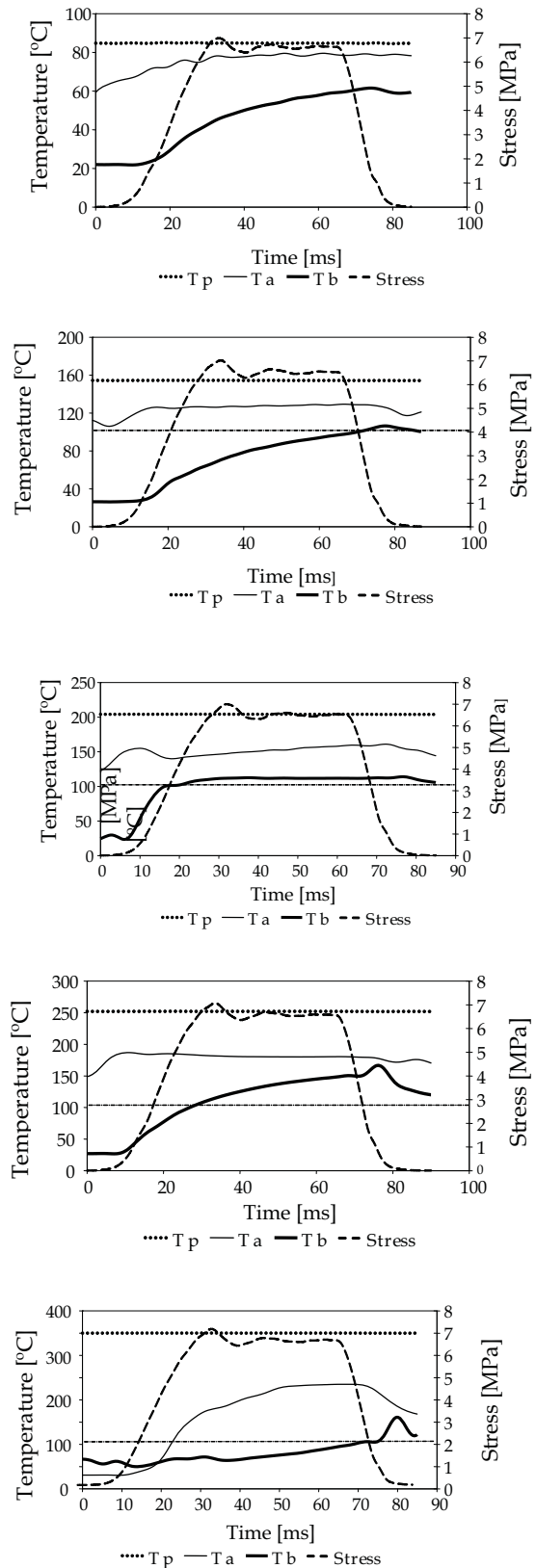

Fig. 8. Internal web temperatures during press drying of $60 \mathrm{~g} . \mathrm{m}^{-2}$ hardwood unsaturated paper samples. The hot plate temperature was set to $80,150,200,250$ and $350{ }^{\circ} \mathrm{C}$ and the nip dwell time was $75 \mathrm{~ms}$. $T_{p}$ is the platen temperature and, $T_{a}$ and $T_{b}$ refer to the temperature at the platen/paper and paper/felt interfaces. (Aguilar Ribeiro, 2006). 
However, at $200^{\circ} \mathrm{C}$ and higher temperatures, a sudden increase of web temperature was recorded when the mechanical load was released. This suggests that thin paper sheets tend to exhibit phase change at the end of the press pulse. The flashing of water as pressure is relieved at the end of the nip is seen as a rapid temperature decrease down to $100{ }^{\circ} \mathrm{C}$. When even shorter pulses $(30 \mathrm{~ms})$ were applied to thin sheets no clear evidence of such temperature increase was found, except for temperatures of $250^{\circ} \mathrm{C}$ or above. As suggested before, this may occur as the increasing compression rate causes an increase in the hydraulic pressure, which may imply almost no in-nip steam generation. According to Lucisano's experimental results, this type of flashing phenomena might only be seen for pulse lengths well beyond those encountered in industrial pressing conditions. Lucisano et al. proposed that this mechanism should be termed "flashing-assisted displacement dewatering" since it differs from the steam-assisted displacement of liquid water originally proposed by Wahren (1982) because of the different driving force (Lucisano \& Martin, 2006).

Despite some similarities in the heat and mass transfer mechanisms involved in the consolidation process of paper and MDF, there are in fact significant technological differences in what concerns the operating conditions of the corresponding industrial pressing/drying units. Table 1 gives an overview of the typical operating conditions for high-intensity pressing and drying of paper and MDF.

\begin{tabular}{|c|c|c|c|c|c|}
\hline \multicolumn{2}{|c|}{} & \multicolumn{3}{c|}{ Paper } & MDF \\
\cline { 2 - 6 } & $\begin{array}{c}\text { Press } \\
\text { drying }\end{array}$ & $\begin{array}{c}\text { Condebelt } \\
\text { drying }\end{array}$ & $\begin{array}{c}\text { Impulse } \\
\text { drying }\end{array}$ & $\begin{array}{c}\text { Hot } \\
\text { pressing }\end{array}$ \\
\hline Mechanical pressure & $\mathrm{MPa}$ & $0.1-0.4$ & $0.02-0.5$ & $1-5$ & $3-4$ \\
\hline $\begin{array}{c}\text { Temperature of } \\
\text { pressing }\end{array}$ & ${ }^{\circ} \mathrm{C}$ & $100-250$ & $120-180$ & $150-500$ & $190-220$ \\
\hline Dwell time & $\mathrm{ms}$ & $200-300$ & $250-10000$ & $\begin{array}{c}5-50 ; 15- \\
100\end{array}$ & - \\
\hline $\begin{array}{c}\text { Maximal outgoing } \\
\text { dryness }\end{array}$ & $\%$ & 45 & - & $>50$ & - \\
\hline $\begin{array}{c}\text { Ingoing moisture } \\
\text { content }\end{array}$ & $\%$ & - & - & - & 11 \\
\hline Machine speed & $\mathrm{m} / \mathrm{min}$ & - & 100 & $>800$ & $7-8$ \\
\hline Web initial thickness & $\mathrm{mm}$ & \multicolumn{5}{|c|}{$0.7-0.8$} & $40-50$ \\
\hline Web final thickness & $\mathrm{mm}$ & \multicolumn{3}{c|}{} & $15-20$ \\
\hline
\end{tabular}

Table 1. Typical operating conditions for continuous high-intensity pressing and drying of paper (adapted from Aguilar Ribeiro, 2006) and MDF (Pereira et al., 2006; Carvalho, 1999; Irle, M. \& Barbu M., 2010).

\section{Modelling of the high-intensity drying processes}

\subsection{Introduction}

The transport mechanisms in high-intensity drying processes are by nature very complex: modelling and simulation of transport mechanisms in a rigid porous medium pose many problems and the situation is even more complicated when the medium is compressible, such as paper and wood-based materials like, for instance, MDF. Moreover, the coupling between heat and mass transfer is strong, making the material description complicated. The 
following sections present a brief description of the main heat and mass transfer models that constitute the basis of the development of more complex models used to explain what happens at high-intensity pressing conditions of highly deformable porous materials, such as paper and MDF. Although special emphasis is given to the main driving mechanisms of water removal (temperature and pressure) it is also worth mention the fundamental role of the fibre network consolidation process, which is here addressed in terms of a structural analysis similar to that used for composite materials.

\subsection{Mechanical models applied to dewatering processes of compressible fibrous networks}

3.2.1 Elasticity, viscoelasticity and plasticity of fibrous composites: paper and MDF

A paper sheet is basically a multiphase material composed of moisture, fibres, voids, and chemical additives, bonded together in a complex network. Thus, it may be considered a composite material, with fibres tending to lie predominantly in the plane of the sheet. Wood itself may be thought of as a natural composite consisting of cellulose fibres interconnected by a primarily lignin binder.

Low and medium-density solids, such as paper and MDF, can therefore be assembled as random networks of fibres, the contact points of which may be bonded together and, according to some authors, mechanical and thermal properties of these materials have much in common with those of cellular materials - honeycombs and foams (Gibson \& Ashby, 1988). The question now is to know the preferred mode of deformation experienced by paper and MDF during drying/pressing operations, and how it can be modelled.

The rheological behaviour of paper or MDF in the course of a pressing event is quite complex: the stresses developed due to densification can be relaxed, blocked in the solid structure, released or originate elastic/plastic deformations. These physical processes are tightly coupled with temperature and humidity distributions; the density profile affects the heat and steam/liquid fluxes across the mattress porous structure. During MDF hot pressing, as the resin cures, it is expected that an increase of stress relaxation take place, because of the formation of a network structure that promotes the development of a uniform distribution of stresses (Carvalho et al., 2003). At the beginning of press closure, the compression of the mat is linear. A yield point is reached, when fibre to fibre contact is made from bottom to top of the mat and wide spread fibre bending occurs (Kamke, 2004). From this point on the compression is nonlinear due to the collapse of cell wall. The fibres begin to compress and lumen starts to diminish. The fibre mat behaves as a viscoelastic material and this behaviour is influenced by temperature, moisture content and time. During the hot-pressing event, it can be considered that the MDF mat responds with elastic strain, delayed elastic strain and viscous strain. The elastic stress is immediately recovered after the removal of stress. The delayed elastic strain is also recoverable but not immediately; in addition, the viscous strain is not recoverable upon removal of the stress (Kamke, 2004). So, the four-element Burger model is frequently used to model this behaviour (Fig. 9a). Pereira et al. (2006) used the burger model for modelling the continuous pressing of MDF. However, irreversible changes of the cell wall and mat structure that happen instantaneously upon loading are not represented by the Burger model. So, to account for both viscoelastic behaviour and the instantaneous but irreversible deformation, Thoemen and Humphrey (2003) considered a modified Burger model with a plastic and micro fracture element in series (represented by a spring that operates only in one direction) - Fig. 9b. Carvalho et al. (2006) and Zombori (2001) considered the Maxwell body (Fig. 9c) as 
an alternative simplified model, due to excessive solution time of their global models for the hot-pressing of MDF and OSB, respectively.

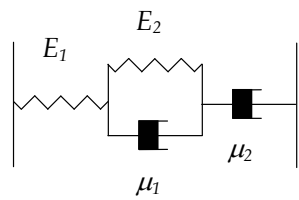

(a) Burger model

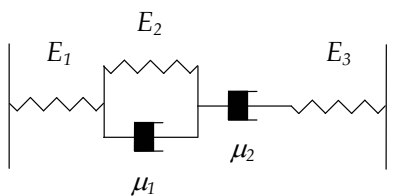

(b) Modified Burger model

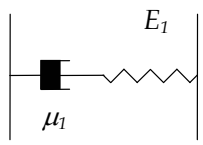

(c) Maxwell model

Fig. 9. Mechanical analogues used to describe the rheological behaviour of MDF throughout a pressing/drying event (Carvalho, 1999).

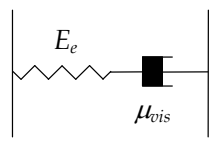

(a) Maxwell model

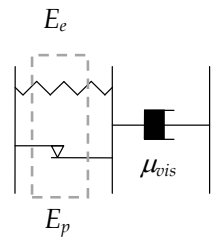

(b) Modified Maxwell model (visco/elastoplastic model)

Fig. 10. Mechanical analogue of the so-called modified Maxwell unit representing the "visco/elastoplastic" model proposed by Aguilar Ribeiro (2006) for the transverse compression of paper in a press nip. $E_{e}$ and $E_{p}$ represent the elastic and plastic moduli of the composite material, respectively.

The rheological behaviour of wet paper samples is somehow similar to MDF mats. When subjected to low loads, paper behaves as a linear elastic material, but under very high loads its stress-strain curve shows a hysteresis. This phenomenon is due to a plastic strain of the web during compression, giving rise to a nonlinear stress-strain curve. In order to model the deformation of paper and MDF during compression, an approach to cellular materials theories is presented in Section 3.2.2. Meanwhile, a brief description of the rheological model for paper is presented herein, taking into account the flow resistance of intra- and extra-fibre water, the contribution of water vapour and air to the elastic modulus of the network, and the fibre rheology itself. At the risk of some simplification, the proposed model may be represented by a mechanical analogue consisting of three elements coupled in series and in parallel (Fig. 10). One element is purely elastic (recoverable), the other is plastic (the unrecoverable strain is associated with the structure of the material), and the third element is viscous (time-dependent). In summary, the elastic and plastic elements characterize the structural integrity of the medium, and the viscous elements the degree to which the medium components move or change position with time when subjected to a stress. In a press nip, paper deforms in three stages. At first, the volume is reduced; as higher pressure is imposed, the fibre network starts to take up load and deformation is achieved through elastic-plastic buckling; at some critical deformation of the fibre network, further deformation can only be achieved by "crushing" of the fibres (Rodal, 1989; Gibson \& Ashby, 1988). Bearing this in mind, Aguilar Ribeiro (2006) proposed a modified Maxwell 
model to describe the nonlinear densification of paper in the pressing section of a paper machine, using simple arrangements of springs, dampers and "dry-friction" elements; the mechanical model has been referred to as "visco/elastoplastic" (Fig. 10).

Considering that strain is only a function of two variables, i.e. time $(t)$ and stress $(\sigma)$, the governing equation for the modified Maxwell model, which defines paper's behaviour when subjected to a dynamic stress, is given by Eq. (4). It clearly states that the total deformation $(\varepsilon)$ of the material may be separated into elastoplastic and viscous deformation. Starting from Hooke's law and taking the derivative form of the equation, it follows that

$$
\sigma=E \cdot \varepsilon \Rightarrow \frac{\partial \sigma}{\partial \varepsilon}=E+\varepsilon \frac{\partial E}{\partial \varepsilon}
$$

As for the viscous constituent of the modified Maxwell unit, it can be represented by Newton's law of viscosity:

$$
\left(\frac{\partial \varepsilon}{\partial t}\right)_{\sigma}=\frac{\sigma}{\mu_{v i s}}
$$

where $\mu_{v i s}$ is the viscous parameter of the network, including the viscosity of its constituents (Aguilar Ribeiro, 2006).

Finally, the governing differential equation for a modified Maxwell element, describing the compression behaviour of paper, may be expressed as

$$
\frac{d \varepsilon}{d t}=\frac{1}{E+\varepsilon \frac{\partial E}{\partial \varepsilon}} \frac{d \sigma}{d t}+\frac{\sigma}{\mu_{v i s}}
$$

A similar approach may be defined for MDF. In this case, a linear viscoelastic behaviour may be assumed, as suggested by Carvalho (1999) - the first term on the right-hand side of Eq. (8) is simplified to $\frac{1}{E} \frac{d \sigma}{d t}$. The following section presents a brief description of the cellular solids theory to estimate the elasticity modulus of the composite materials (E), paper and MDF.

\subsubsection{Application of cellular solids theory to paper and wood-based materials}

The applicability of the cellular material compression theories to describe the nonlinearity of the transverse compression of solid wood has been demonstrated by several authors (Wolcott et al., 1989; Lenth \& Kamke, 1996a; Lenth \& Kamke, 1996b; Easterling et. al, 1982). This same approach has been used to describe the consolidation of MDF and paper by Carvalho (1999) and Aguilar Ribeiro (2006), respectively.

In a press nip of a paper machine, as the fibre network becomes compacted, a hydraulic pressure builds up in the water held within the fibre walls (intra-fibre water) and a part of it is driven out (Carlsson, 1983; Vomhoff, 1998). Thus, only a part of the structural stress is due to the mechanical stiffness of the fibre network (Szikla \& Paulapuro, 1989a, 1989b). The main resistance is due to the flow of the intra-fibre water within and out of the fibre walls, which is inherently a viscous phenomenon. The rheology of the fibre network can therefore be expected to be rate-dependent, and a model of the fibre network rheology should capture the mechanical stiffness and the stress due to the flow resistance inside the fibres. From a 
composite point of view, the "elastoplastic" modulus of a paper sheet $(E)$ is therefore seen as the sum of the contributions of both solid and fluid phases. Consequently, the following relation based on the longitudinal rule of mixtures can be written,

$$
E=E_{s} \phi_{s}+E_{g} \phi_{g}+E_{l} \phi_{l}
$$

where $\phi_{s}, \phi_{g}$ and $\phi_{l}$ represent the volume fractions of the solid, gas and liquid phases in the composite material.

In addition, it is known that for cellular materials, the elasticity modulus $(E)$ depends both on strain and relative density of the solid $\left(\rho_{\text {rel }}\right.$ - defined as the ratio of the apparent density of the porous material (cell wall material + additives + adsorbed water), $\rho$, to the real density of the solid of which it is made, $\rho_{s}$ ). This relation has been described by Gibson and Ashby (1988) for closed cellular solids as

$$
E=C_{2} E_{c w} \rho_{r e l}^{\alpha}
$$

where $C_{2}$ is a constant, $E_{c w}$ the elasticity modulus of the fibre cell wall material, and a a parameter which is a function of the material structure $(1.5<\alpha<3.0)$. Bearing in mind the water removal mechanisms occurring in a paper pressing event, Aguilar Ribeiro (2006) considered the "open-celled foam" version of Eq. (10) to estimate the elasticity modulus of the fibrous solid structure (Maiti et al., 1984). The solid matrix is therefore assumed to consist of open interconnected cells through which fluids (liquid water, air and water vapour) flow as a consequence of material deformation:

$$
E=C_{2} E_{c w} \rho_{r e l}^{2}
$$

Finally, it is worth mention that Eq. (9) is derived from Hooke's law for linear elasticity, and this is not valid for the paper and MDF consolidation process since these materials exhibit nonlinear behaviour. As such, the corresponding compressive stress-strain curves are represented by the modified Hooke's law, which takes into account the linear as well as the nonlinear mechanical response of the material by introducing an additional nonlinearising term, $\Phi\left(\varepsilon, \rho_{r e l}\right)$ (Gibson \& Ashby, 1988; Maiti et. al, 1984). Eq. (9) may now be written in its final form as

$$
E=C_{2} E_{s} \rho_{r e l}^{2} \Phi\left(\varepsilon, \rho_{r e l}\right)+E_{g} \phi_{g}+E_{l} \phi_{l}
$$

where $E_{s}$ accounts for the fibre cell wall material, adsorbed water on the surface of the cellulose fibres, and any possible additives or resins used in the fibre stock preparation.

\subsection{Heat and mass transfer models}

\subsubsection{Simultaneous heat and mass transfer models for paper and MDF}

A rigorous model for high-temperature pressing of paper and other wood-based materials will involve the simultaneous solution of a wet pressing model and a heat transfer model. Such a model will be extremely complex and highly non-linear, especially if phase-change phenomena are to be included.

Heat and mass transfer models for MDF: batch, continuous and HF pressing

Since the eighties, several models have been published in the literature for the batch process, mostly for particleboard. However, these models have inherent limitations, either because 
they are one-dimensional or do not couple all the phenomena involved in the process. The first models that were developed for the hot-pressing of particleboard attempted to describe only simultaneous heat and mass transfer (Kamke \& Wolcott, 1991). The improvement of computer performance induced the development of two or three-dimensional models, although with some limiting simplifications, namely treating the problem as pseudo-steadystate (Humphrey \& Bolton, 1989) or simply predicting the behaviour of a single variable (Hata et al., 1990). For MDF, a three-dimensional unsteady-state model was presented (Carvalho \& Costa, 1998), describing the heat and mass transfer. A global model, integrating all the mechanisms involved (rheological behaviour and resin polymerisation reaction) was also presented later (Carvalho et al., 2003). Almost at the same time, a combined stochastic deterministic model was developed by Zombori $(2001,2002)$ to characterise the random mat formation and the physical mechanisms during the hot-pressing of OSB. A two-dimensional model of heat and mass transport within an oriented strand board (OSB) mat, during the hot pressing process, was presented also by Fenton et al. (2003). This model was later combined with a model to predict mat formation and compression (Painter el al., 2006a) and another to predict the mechanical properties (Painter et al., 2006b). The global model was also used in a genetic algorithm to carry out an optimisation study of batch OSB manufacturing (Painter et al., 2006b). Dai and Yu (2004, Dai et al., 2007) presented a model that provides a mathematical description of the coupled physical phenomenon in hot-pressing of OSB. This model was then validated with experimental data (temperature and gas pressure inside the mat) (Dai et al., 2007).

As for the continuous pressing, the description of the phenomena involved corresponds to the modelling of a porous and heterogeneous media in movement. The main difficulty associated to this type of problems is the choice of the reference system to make easy the numerical solution of the equations of conservation of mass, energy and momentum. While the batch process represents an unsteady state problem, the continuous process can be described as a steady-state process using the press as the reference system. Thoemen and Humphrey (1999, 2001, 2003) presented an analytical model that is based on thermodynamics, rheological concepts and numerical solution used by Humphrey. This model accounts for combined heat and mass transfer, adhesive cure, mat densification and stress relaxation. Lee (2006) presented an optimisation of OSB manufacturing that focused on the continuous pressing process, but did not consider mechanical strength of the panel. Pereira et al. (2006) presented a three-dimensional model for the continuous pressing of MDF. A comprehensive description of the mechanisms involved, as well as the equations and the numerical method used for solving this problem were described. The set of equations for the conservation of energy, mass and momentum was deduced in an Eulerian reference system (taking the press as reference), then changed to a moving reference system (taking the mat as reference) and finally solved as an unsteady-state problem.

An alternative to the hot-platen heating is the use of high frequency heating, which has the advantage of reducing the duration of the pressing cycle, the platen temperature and the post-curing time, for the same resin formulation. The reported work on modelling of HF heating in the production of wood-based panels is scarce. Pereira et al. (2004) presented an electromagnetic heating model that was coupled with a three-dimensional model for heat and mass transfer and resin polymerisation previously presented. This dynamic model was used to predict the evolution of the local variables related to heat and mass transfer (temperature and moisture content), as well as the variable connected to the electromagnetic behaviour (dielectric properties of the mat). 
Heat and mass transfer models for paper: high-intensity processes and impulse drying

Phase-change problems in which a phase boundary moves have received much attention in recent years, and impulse drying of paper is just an example. Here, and according to some authors (Ahrens, 1984; Pounder, 1986), the vapour-liquid boundary moves not only because of phase-change but also the liquid is driven out by the generated vapour pressure. Impulse drying is also related to another set of moving boundary problems involving phase displacement in porous media. Pounders (1986) and Ahrens (1984) presented a model for high-intensity drying of paper, which could be applied to impulse drying. The drying process is idealized in the sense that paper is divided in different zones comprising different amounts of fibre, liquid water and water vapour. The model is based on solving the conservation equations of heat and mass in the different zones, combining equations which describe the applied pressure and the physical properties of liquid and vapour, as well as equations describing the thermal properties, compressibility and permeability of paper. From their study it was found that in many cases the model predicted a higher degree of water removal than that observed in press drying experiments. Later, Lindsay (1991) proposed a model in which vapour and liquid are assumed to be in equilibrium in a twophase zone between the dry zone (close to the hot surface of the press machine) and the wet zone (near the felt). Heat transfer is then governed by evaporation occurring at the dry interface and condensation at the wet interface, thus predicting an almost constant temperature profile within the two-phase zone. Experimental temperature profiles used for comparison in his study showed similar behaviour, a plateau of almost constant temperature. In addition, Lindsay found that the model could predict the heat fluxes during impulse drying, showing the basic features found in the experimental investigations, but they were somehow overestimated.

Unlike the earlier authors, Riepen (2000) proposed a model in which conduction and convective heat transfer was considered. His model includes the coupling of a wet pressing model and a heat transfer model, and it describes the transfer of mass and energy through the paper, providing the possibility of studying flash expansion during nip opening. According to Riepen's model, the steam formed could increase the hydraulic pressure and thus the hydraulic pressure gradient across the paper thickness, which is the driving force in the impulse drying dewatering process (Riepen, 2000).

In an effort to use a simple model describing the dewatering process in impulse drying, Nilsson and Stenström (2001) treated paper as a two-phase medium of cellulose fibres and water where the two components constitute a homogeneous matrix. The model is based on solving the energy equations for a compressible medium and is limited to the compression phase of the impulse drying event, without phase change and not considering the structural aspects of the fibrous network. According to the authors, the good agreement between the predicted temperature profiles and the experiments performed at elevated temperatures reinforces the assumption that impulse drying is a process with enhanced wet pressing due to the increased web temperature followed by flashing of superheated water. In addition, they advanced that heat conduction and convection are always present regardless of the temperature and pressure (and the transport mechanisms involved in impulse drying can occur simultaneously in different parts of the web), although the convective heat transfer is low and of minor importance (Nilsson \& Stenström, 2001).

Gustafsson and Kaul (2001) presented a general model of wet pressing at high temperature, in which the fibrous network rheology was described by the model suggested by Lobosco and Kaul (2001). The model includes the rate dependency of the fibre network stress and thus takes into account the flow resistance of the intra-fibre water, something not done in 
previous works. The capability of the model to predict changes in the solids content and structural properties of the fibre web as it passes through the press nip was good within the range of temperatures and linear loads studied by the authors.

More recently, a similar approach was used to describe the consolidation of paper in an impulse drying event taking into account its nonlinear behaviour to compression resembling that of cellular structures (Aguilar Ribeiro, 2006; Aguilar Ribeiro \& Costa, 2007a). Paper is seen as a medium composed of three phases, solid, liquid and gas (air and water vapour) in thermodynamic equilibrium; and three main heat and mass transfer mechanisms are assumed: heat conduction, convective heat and mass transfer, and phase change of water either from the adsorbed or liquid state into vapour. A brief description of the model is presented hereafter, and a more detailed explanation can be found elsewhere (Aguilar Ribeiro, 2006; Aguilar Ribeiro \& Costa, 2007a; Aguilar Ribeiro \& Costa, 2007b).

The development of a mathematical model for any system involves the formulation of equations describing the physics of the process based on the fundamental laws of conservation of matter and energy. For high temperature pressing, five coupled equations have to be solved to calculate the heat and mass transfer in the wet fibre web: the continuity equations for free liquid water (if it exists), water vapour, gas phase and energy; and one equilibrium equation (moisture sorption isotherm or one describing the liquid/vapour saturation). Finally, the mechanical behaviour of the mat to compression is described by one equation that relates the vertical position in the web thickness direction and local deformation, one to determine the stress development inside the mat, and one equation for the total thickness of the web. The description of the model presented hereafter does not intend to be exhaustive, but rather give some insight into the main constitutive equations that govern the heat and mass transfer phenomena during a press/drying event of a wet fibre mat, such as paper or MDF. In particular, this work focus the compression of a paper web as it passes through the nip of an impulse drying unit of a paper machine. A more complete and detailed description of the models can be found elsewhere (Aguilar Ribeiro, 2006; Aguilar Ribeiro \& Costa, 2007a; Aguilar Ribeiro \& Costa, 2007b; Carvalho, 1999).

\subsubsection{The energy conservation equation}

The first term in Eq. (13) refers to the accumulation of heat in the wet web followed by the terms concerning the liquid/vapour phase change, which equal the conductive and convective heat fluxes in the three main directions, $x, y$ and $z$ (machine, cross-machine and thickness direction, respectively):

$$
\left(\rho C_{p} \frac{\partial T}{\partial t}+C_{p} T \frac{\partial \rho}{\partial t}\right)+\dot{M}\left(\Delta H_{v a p}+Q_{l}\right)=-\left(\frac{\partial \varphi_{t_{x}}}{\partial x}+\frac{\partial \varphi_{t_{y}}}{\partial y}+\frac{\partial \varphi_{t_{z}}}{\partial z}\right)
$$

where $T$ is the temperature inside the mat, $\rho$ and $C_{p}$ are the density and the specific heat

capacity of the mat, $\dot{M}$ the amount of vaporised water per unit time and volume, $\Delta H_{v a p}$ the latent heat of vaporisation of water, $Q_{l}$ the differential heat of sorption for the wood-water system, and $\varphi_{t_{i}}(i=x, y, z)$ is the total heat flux in the three main directions of the mat defined as

$$
\varphi_{t_{i}}=-\lambda_{i} \frac{\partial T}{\partial i}+\left(\rho_{g} v_{g_{i}} C_{p_{g}}+\rho_{l} v_{l_{i}} C_{p_{l}}\right) T
$$


where $\lambda_{i}$ is the thermal conductivity of the mat in a given $i$ direction, $\rho_{g}, \rho_{l}, C_{p_{g}}$ and $C_{p_{l}}$ the specific densities and heat capacities of both gas and liquid phases, and finally $v_{g_{i}}$ and $v_{l_{i}}$ represent the superficial velocity of gas and liquid in the three main directions defined by Darcy's law.

\subsubsection{The mass conservation equations: liquid and gas phases}

\section{Water vapour phase}

To establish the mass balance for water vapour, two possible scenarios may be drawn: (i) below the fibre saturation point: at this stage there is no free liquid water in the web, which means that the vapour formed comes entirely from the vaporisation of the adsorbed water on the cellulose fibres (this is the case of MDF, in which only adsorbed water is present); (ii) above the fibre saturation point: as adsorbed water is assumed to be retained on the surface of the cellulose fibres, the liquid water is considered to be in equilibrium with its saturated vapour. The water vapour mass balance may then be expressed as:

$$
\left(\dot{M}_{b}+\dot{M}_{l}\right)=\frac{\partial\left(\phi_{g} \rho_{v}\right)}{\partial t}+\left(\frac{\partial \varphi_{v_{x}}}{\partial x}+\frac{\partial \varphi_{v_{y}}}{\partial y}+\frac{\partial \varphi_{v_{z}}}{\partial z}\right)
$$

where $\dot{M}_{b}$ and $\dot{M}_{l}$ are the amount of adsorbed or liquid water vaporised per unit time and volume, $\phi_{g}$ is the volume fraction of gas (air and water vapour) in the entire mat, $\rho_{v}$ the specific density of vapour and $\varphi_{v_{i}}$ is the total water vapour flux in the $i$ direction defined as:

$$
\varphi_{v_{i}}=\rho_{v} v_{g_{i}}-\phi_{g} D_{i}^{e f f} \frac{\partial \rho_{v}}{\partial i}=\frac{M M_{v}}{R}\left[\frac{P_{v}}{T} v_{g_{i}}-\phi_{g} D_{i}^{e f f} \frac{\partial}{\partial i}\left(\frac{P_{v}}{T}\right)\right]
$$

$D_{i}^{e f f}$ is the effective diffusivity of water vapour in the pores of the mat for a given $i$ direction, $M M_{v}$ the molar mass of water, $R$ the universal gas constant and $P_{v}$ the vapour partial pressure.

Gas phase (air + water vapour)

Following the same approach used for the vapour mass balance, the conservation equation for the gas phase may be written as:

$$
\left(\dot{M}_{b}+\dot{M}_{l}\right)=\frac{\partial\left(\phi_{g} \rho_{g}\right)}{\partial t}+\left(\frac{\partial \varphi_{g_{x}}}{\partial x}+\frac{\partial \varphi_{g_{y}}}{\partial y}+\frac{\partial \varphi_{g_{z}}}{\partial z}\right)
$$

where $\rho_{g}$ is the specific density of the gas phase, and the gas flux in the $i$ direction $\left(\varphi_{g_{i}}\right)$ is given by:

$$
\varphi_{g_{i}}=\rho_{g} v_{g_{i}}=\rho_{g}\left(-\frac{K_{g_{i}}}{\mu_{g}} \frac{\partial P_{g}}{\partial i}\right)
$$

and $K_{g_{i}}$ and $\mu \mathrm{g}$ are the permeabilities and the viscosity of the gas phase in the porous medium. 


\section{Liquid phase}

When the material is above the fibre saturation point, the amount of vapour generated comes from the liquid phase in equilibrium with its saturated vapour (in this case, $\dot{M}=\dot{M}_{l}$ and $\dot{M}_{b}=0$ ). Therefore, the amount of vaporised liquid is defined by the liquid/vapour equilibrium relation:

$$
P_{v}=P^{\text {saturation }}=f(T) \Rightarrow \frac{\partial P_{v}}{\partial t}=\frac{\partial P^{\text {saturation }}}{\partial t}=\left(\frac{\partial P^{\text {saturation }}}{\partial T}\right)\left(\frac{\partial T}{\partial t}\right)
$$

The mass balance for the liquid phase is then expressed as:

$$
\frac{\partial\left(\phi_{l} \rho_{l}\right)}{\partial t}=-\left(\frac{\partial \varphi_{l_{x}}}{\partial x}+\frac{\partial \varphi_{l_{y}}}{\partial y}+\frac{\partial \varphi_{l_{z}}}{\partial z}\right)-\dot{M}_{l}
$$

where $\rho_{l}$ is the specific density of the liquid phase, and the water flux in the $i$ direction $\left(\phi_{l_{i}}\right)$ is given by:

$$
\varphi_{l_{i}}=\rho_{l} v_{l_{i}}=-\frac{\rho_{l} K_{l_{i}}}{\mu_{l}}\left(\frac{\partial P_{g}}{\partial i}-\frac{\partial P_{c}}{\partial i}\right)
$$

and $K_{l_{i}}, \mu \mathrm{l}$ and $P_{c}$ are the permeabilities, the viscosity and the capillary pressure of the liquid water in the porous medium.

On the other hand, if no liquid water is present in the mat (this is the case for MDF), the vapour results exclusively from the vaporisation of adsorbed water which is now in equilibrium with the vapour in the pores (in this case, $\dot{M}=\dot{M}_{b}$ and $\dot{M}_{l}=0$ ). Therefore, the water/vapour equilibrium may be described by a sorption isotherm as that derived by Nadler et al. (1985). The relative humidity, $R H$, and the moisture ratio at the equilibrium (here defined as $M R_{e q}$ ) are related by the following equation:

$$
M R_{e q}=f(R H)=f\left(\frac{P_{v}}{P^{\text {saturation }}}\right)
$$

Assuming that the amount of water being vaporised per unit time and volume is given by the variation of the moisture ratio of the web,

$$
\dot{M}_{b}=-\frac{\partial m_{b}}{\partial t}=-\frac{\partial}{\partial t}\left(\frac{m_{d r y} \cdot M R_{e q}}{V}\right)=-\frac{\partial}{\partial t}\left(\rho_{d r y} \cdot M R_{e q}\right)
$$

where $\rho_{d r y}$ is the apparent density of the dry solid defined as the mass of the fibre cell wall material and additives, $m_{d r y}$, per unit volume $V$.

Finally, if no liquid water is present in the web, Eq. (19) may be rewritten as follows:

$$
\frac{\partial P_{v}}{\partial t}=\frac{P^{\text {saturation }}\left(\frac{\partial M R_{e q}}{\partial t}\right)}{\left(\frac{\partial M R_{e q}}{\partial R H}\right)_{T}}=-\frac{\frac{P^{\text {saturation }}}{\rho_{d r y}}\left(\dot{M}_{b}+M R_{e q} \frac{\partial \rho_{d r y}}{\partial t}\right)}{\left(\frac{\partial M R_{e q}}{\partial R H}\right)_{T}}
$$




\subsubsection{The momentum conservation equation}

The governing differential equations describing the consolidation of the web take into account the viscoelastic behaviour of the mat under compression, as explained in section 3.2. According to the mat discretisation grid, used to model the entire mat (Fig.11), the vertical position for each ijk representative volume element is given by Eq. (25a).

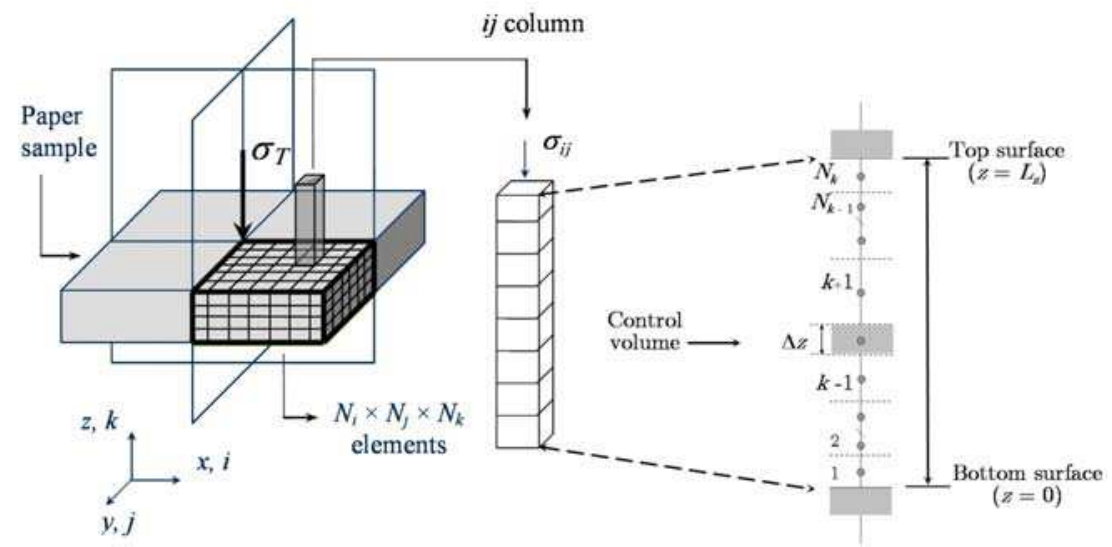

Fig. 11. Schematic representation of the mechanical model in compression, with discretisation in the thickness direction of the web (here divided in $N_{i} \times N_{j} \times N_{k}$ control volumes) (Aguilar Ribeiro, 2006).

$$
\frac{\partial z_{i j k}}{\partial t}=\frac{\Delta z_{0}}{2}\left(\frac{\partial \varepsilon_{i j k}}{\partial t}+2 \sum_{l=1}^{k-1} \frac{\partial \varepsilon_{i j l}}{\partial t}\right)
$$

with

$$
\frac{\partial \varepsilon_{i j k}}{\partial t}=\frac{1}{E_{i j k}+\varepsilon_{i j k} \frac{\partial E_{i j k}}{\partial \varepsilon_{i j k}}} \frac{\partial \sigma_{i j k}}{\partial t}+\frac{\sigma_{i j k}}{\mu_{i j k}}
$$

The applied stress in every $i j$ column of the web $\left(\sigma_{i j}\right)$ may be expressed in terms of the local deformation $\left(\varepsilon_{\mathrm{ij}}\right)$ :

$$
\frac{\partial \sigma_{i j}}{\partial t}=E_{i j} \frac{\partial \varepsilon_{i j}}{\partial t}-\frac{E_{i j}}{\mu_{i j}} \sigma_{i j}
$$

with

$$
E_{i j}=\frac{N_{k}}{\sum_{k=1}^{N_{k}} \frac{1}{E_{i j k}+\varepsilon_{i j k} \frac{\partial E_{i j k}}{\partial \varepsilon_{i j k}}}}
$$




$$
\mu_{i j}=\frac{N_{k}}{\sum_{k=1}^{N_{k}} \frac{1}{\mu_{i j k}}}
$$

where $E_{i j}$ and $\mu_{\mathrm{ij}}$ are the elastic and viscous parameters defined for each $i j$ column. Again, for the entire mat it will be assumed the same rheological behaviour, i.e. the total deformation of the fibrous network $\left(\varepsilon_{\mathrm{T}}\right)$ is described by the viscoelastic constitutive relation:

$$
\begin{gathered}
\frac{\partial \varepsilon_{T}}{\partial t}=\frac{1}{E_{T}} \frac{\partial \sigma_{T}}{\partial t}+\frac{\sigma_{T}}{\mu_{T}} \\
E_{T}=\frac{1}{N_{i} N_{j}} \sum_{i j} E_{i j} \\
\mu_{T}=\frac{1}{N_{i} N_{j}} \sum_{i j} \mu_{i j}
\end{gathered}
$$

where the subscript " $\mathrm{T}$ " refers to the entire structure. The initial and boundary conditions, as well as the physical, mechanical and thermodynamic properties of the web, required to solve this set of partial differential equations are described elsewhere (Aguilar Ribeiro, 2006; Aguilar Ribeiro \& Costa, 2007a; Aguilar Ribeiro \& Costa, 2007b; Carvalho, 1999).

\section{Technological barriers and future perspectives}

Although the knowledge concerning the phenomena involved in high temperature pressing of paper, including impulse drying, has increased tremendously over the years, modelling and simulation of the process must me continued. Improvements and extensions are required to describe the post-nip stage of the process and to clarify the amount and severity of the flash expansion. As the highest temperature occurs at the paper side in contact with the heated cylinder of the press machine, the application of coatings with special thermal properties (high thermal mass) at this interface would influence the interface temperature as well as the distribution inside the paper sheet and most probably reduce the effects of flash expansion.

Concerning wood-based panels, advances particularly in the fields of adhesive formulation, production technology, as well as online measuring and control techniques, have triggered a technology push in the manufacture of these materials (Thoemen, 2010). However, in the majority of production lines, the scheduling of the press cycle is still done empirically, based on a trial and error methodology in the production line. Models are important tools for the scheduling of the press cycle as well as for the prediction of the final product properties, but technological barriers still exist for the direct application in industry. Despite the advances on computer modelling in other areas during the last two decades, the full potential of today's models have not been exploited yet, and not all the models meet the needs of the industry (COST Action E49, 2004). The increase in complexity (real world conditions, raw material variability due to the use of wood residues and recycled wood) and the need for faster numerical solutions (real time simulator) might well be the driving forces for the use of other numerical strategies, including the use of artificial intelligence methods (genetic algorithms, neural networks, fractals) and distributed agents methods. 


\section{References}

Aguilar Ribeiro, H. (2006). Study of the rheology of deformable porous media: application to paper production. PhD thesis, University of Porto, Portugal.

Aguilar Ribeiro, H. \& Costa, C.A.V. (2007a). Modeling and Simulation of the Hot-Pressing Process in Paper Production: A Heat- and Mass-Transfer Analysis. Industrial $\mathcal{E}$ Engineering Chemistry Research, 46, 24, 8205-8219.

Aguilar Ribeiro, H. \& Costa, C.A.V. (2007b). Modelling and simulation of the Nonlinear Behavior of Paper: A Cellular Materials Approach. Chemical Engineering Science, 62, 6696-6708.

Ahrens, F. (1984). Fundamentals of drying. Technical Report Project 3470, The Institute of Paper Chemistry, USA.

Arenander, S. \& Wahren, D. (1983). Impulse drying adds new dimension to water removal. Tappi Journal, 66, 9, 123-126.

Athanassiadou, E.; Tsiantzi, S. \& C. Markessini (2007). Towards composites with formaldehyde emission at natural wood levels, In: COST Action E49 'Measurement and Control of VOC Emissions from Wood-Based Panels', Braunschweig, Germany.

Bowen, M.E. (1970). Heat transfer in particleboard during hot-pressing. PhD dissertation, Colorado State University, Corvallis, USA.

Burns, J.R.; Connors, T.E. \& Lindsay, J.D. (1990). Dynamic measurement of density gradient development during wet pressing. Tappi Journal, 73, 4, 107- 113.

Campbell, W.B. (1947). The physics of water removal. Pulp and Paper Magazine of Canada, 48, 3, 103-109.

Carlsson, G. (1983). Some Fundamental Aspects of the Wet Pressing of Paper. PhD thesis, Royal Institute of Technology, Sweden.

Carlsson, G.; Lindström, T. \& B. Norman (1982). Some basic aspects on wet pressing of paper, In: IPC International Water Removal Symposium, 5-12, CPPA, Vancouver, Canada.

Carlsson, G.; Lindström, T. \& Söremark, C. (1977). Expression of Water from Cellulosic Fibers under Compressive Loading, Transactions of the British Paper and Board Industry Federation Symposium on Fiber - Water Interactions in Papermaking, 389-409, British Paper and Board Industry Federation, Oxford, UK.

Carvalho L. (1999). Estudo da Operação de prensagem do Aglomerado de Fibras de Média Densidade: Prensa descontínua de pratos quentes (Study of the hot-pressing of Medium Density Fiberboard (MDF): batch platen press). PhD Thesis in Chemical Engineering, Faculty of Engineering of University of Porto, Portugal.

Carvalho, L.H.; Costa, M.R.N. \& Costa, C.A.V. (2003). A Global Model for the Hot-Pressing of Medium Density Fiberboard (MDF). Wood Sci. and Technol., 37, 241-258.

Carvalho, L.M. \& Costa, C.A.V. (1998). Modeling and simulation of the hot-pressing process in the production of medium density fiberboard (MDF). Chem. Eng. Comm., 170, 1-21.

Carvalho, L.M. (2008). Modelling of the Hot-Pressing Process, In: Core Document of COST E34 "Bonding of Timber", Lignovisionen issue 18, 197-201, Universität für Bodenkultur, ISSN 1681-2808, Wien, Austria.

Confederation of European Paper Industries (2010). Key Statistics 2009 - European Pulp and Paper Industry. CEPI, Brussels.

Constant, T.; Moyne, C. \& Perré, P. (1996). Drying with internal heat generation: theoretical aspects and application to microwave heating. AIChE J., 42, 2, 359-368.

COST Action E49 (Processes and Performance of Wood-based Panels) "Memorandum of Understanding", 2004.

Dai, C. \& Yu, C. (2004). Heat and mass transfer in wood composite panels during hotpressing: Part I. A physical-mathematical model. Wood and Fibre Sci., 36, 4, 585-597. 
Dai, C.; Yu, C.; Xu C. \& He, G. (2007). Heat and mass transfer in wood composite panels during hot pressing: Part 4. Experimental investigation and model validation. Holzforshung, 61, 83-88.

Denisov, O.B.; Anisov, P. \& Zuban P.E. (1975). Untersuchung der Permeabilität von Spanvliesen. Holztechnologie, 16, 1, 10-14.

Devlin, C.P. (1986). An Investigation of the Mechanism of High-Intensity Paper Drying. PhD thesis, Institute of Paper Chemistry, USA.

Easterling, K.E.; Harrysson, R.; Gibson, L.J. \& Ashby, M.F. (1982). On the mechanics of balsa and other woods. Proceedings of the Royal Society of London, Vol. A383, No. 1784 (September, 1982), 31-41.

Fenton, T.; Budman, H.; Pritzker, M.; Bernard, E. \& Broderick, G. (2003). Modeling of Oriented Strandboard Pressing. Ind. Eng. Chem. Res., 42, 5229-5238.

Gibson, L. \& Ashby, M. (1988). Cellular Solids: Structure and Properties. Pergamon Press, ISBN 0521495601, Oxford.

Gustafsson, J.-E. \& Kaul, V. (2001). A general model of deformation and flow in wet fibre webs under compression. Nordic Pulp and Paper Research Journal, 16, 2, 149-155.

Hata, T.; Kawai, S. \& Sasaki, H. (1990). Computer simulation of temperature behavior in particle mat during hotpressing and steam injection pressing. Wood Sci. and Technol., 24, 65.

Humphrey, P.E. \& Bolton, A.J. (1989). The Hot Pressing of Dry-formed Wood-based Composites. Part II: A Simulation Model for Heat and Moisture Transfer, and Typical Results. Holzforschung, 43, 3, 199-206.

Humphrey, P.E. (1982). Physical aspects of wood particleboard manufacture. Ph.D. Thesis, University of Wales, UK.

Irle, M. \& Barbu M. (2010). Wood-Based Panel Technology, In: Wood-based Panels: An Introduction to Specialists, H. Thoemen, M. Irle \& M. Sernek (Ed.), 1-94, Brunel University Press, ISBN 978-1-902316-82-6, London, England.

Kamke, F.A. (2004). Physics of Hot-pressing, In: Fundamentals of Composite Processing: Proceedings of a Workshop, 3-18, USDA Forest Service, General Technical Report FPLGRT-149, Madison WI, U.S.A.

Kamke, F.A. \& Casey, L.J. (1988). Fundamentals of flakeboard manufacture: internal-mat conditions. For. Prod. J., 38, 6, 38- 44.

Kamke F.A. \& Wolcott, M.P. (1991). Fundamentals of flakeboard manufacture: woodmoisture relationships. Wood Sci. and Technol., 25, 57.

Kataja, M.; Kirmanen, J. \& Timonen, J. (1995). Hydrostatic and structural pressure in compressed paper webs and press felts. Nordic Pulp and Paper Research Journal, 10, 3, 162-166.

Kavvouras, P.K. (1977). Fundamental process variable in particleboard manufacture, Ph.D. Thesis, University of Wales, UK.

Larsson, H. \& Stenström, S. (1998). Critical pressure control of delamination in impulse drying. Tappi Journal, 81, 7, 117-122.

Larsson, H.; Nilsson, J. \& Stenström, S. (2001). Experiments in a pilot-scale impulse unit Part I: Heat transfer and water removal rates. Nordic Pulp and Paper Research Journal, 16, 156-161.

Lavery, H.P. (1987). Impulse drying of linerboard, Proceedings of the TAPPI Papermakers Conference, pp. 43-49, Atlanta, GA, April 1987, TAPPI Press, Norcross, GA.

Lee, C.; Budman, H. \& Pritzker, M. (2006). Simulation and Optimisation of the Continuous Oriented Strand Board Pressing Process. Ind. Eng. Chem. Res., 45, 6, 1974-1988.

Lenth, C.A. \& Kamke, F.A. (1996a). Investigations of flakeboard mat consolidation. Part I. Characterizing the cellular structure. Wood and Fiber Sci., 28, 2, 153-167. 
Lenth, C.A. \& Kamke, F.A. (1996b). Investigations of flakeboard mat consolidation. Part II. Modeling mat consolidation using theories of cellular materials. Wood and Fiber Sci., 28, 3, 309-319.

Lindsay, J.D. \& Sprague, C.H. (1989). MIPPS: A numerical moving-boundary model for impulse drying. Journal of Pulp and Paper Science, 15, 4, J135-141.

Lindsay, J.D. (1991). Advances in the numerical modeling of impulse drying, In: Tappi Engineering and Management in the Pulp and Paper Industry, M. J. Coleman (Ed.), 665677, Tappi Press, Atlanta, GA, USA.

Lobosco, V. \& Kaul, V. (2001). An Elastic/Viscoplastic model of the fibre network stress in wet pressing: Part I. Nordic Pulp and Paper Research Journal, 16, 1, 1217.

Lucisano, M.F.C. (2002). On Heat and Paper: From Hot Pressing to Impulse Technology. PhD thesis, Royal Institute of Technology, Sweden.

Lucisano, M.F.C. \& Martin, A.R. (2006). Visualization of liquid-vapor phase change phenomena in impulse technology. Tappi Journal, 5, 6, 15-21.

Lucisano, M.F.C.; Mazzatorta, P. \& Martinez, D.M. (2001). On the mechanism of steam forming during impulse pressing of wet paper webs. Nordic Pulp and Paper Research Journal, 16, 4, 355-361.

MacGregor, M.A. (1983). A description of sheet stratification caused by wet pressing. Tappi Journal, 66; 6, 53-57.

Macklem, E.A. \& Pulkowski, J.H. (1988). Impulse drying - a pressing/flashing drying phenomenon, Proceedings of the TAPPI Engineering Conference, pp. 447-453, Chicago, IL, September 1988, TAPPI Press, Norcross, GA.

Maiti, S.K.; Gibson, L.J. \& M.F. Ashby (1984). Deformation and energy absorption diagrams for cellular solids. Act. Metal, 32, 11, 1963-1975.

Metso Paper (2010). http://www.metso.com/pulpandpaper/MPwUpRunning.nsf/ WebWID/WTB-090603-2256F-67CFF?OpenDocument (December 13, 2010).

Nilsson, J. \& Stenström, S. (2001). Modelling of heat transfer in hot pressing and impulse drying of paper. Drying Technology: An International Journal, 19, 10, 2469-2485.

Orloff, D.I.; Patterson, T.F. \& Parviainen, P.M. (1998). Opening the operating window of impulse drying - Part II: Pressure differential as a source of delamination. Tappi Journal, 81, 8, 195-203.

Painter, G.; Budman, H. \& Pritzker, M. (2006a). Prediction of oriented strand board properties from mat formation and compression operating conditions. Part 1. Horizontal density distribution and vertical density profile. Wood Sci. and Technol., 40, 139-158.

Painter G.; Budman, H. \& Pritzker, M. (2006b). Prediction of oriented strand board properties from mat formation and compression operating conditions. Part 2: MOE prediction and process optimization. Wood Sci. and Technol., 40, 291-307.

Pereira, C.; Carvalho, L.H. \& Costa, C.A.V. (2004). High Frequency Heating of Medium Density Fiberboard (MDF): Theory and Experiment. Chem. Eng. Sci., 59, 4, 735-745.

Pereira, C.; Carvalho, L.H. \& Costa, C.A.V. (2006). Modeling the continuous hot-pressing of MDF. Wood Sci. and Technol., 40, 308-326.

Pikulik, I. (1999). The Effects of Shoe Pressing on Fine Paper Properties. Tappi Journal, 82, 11 88-92.

Pounder, J. ( 1986). A Mathematical Model of High Intensity Paper Drying. PhD thesis, The Institute of Paper Chemistry, USA.

Riepen, M. (2000). An inside view on impulse drying phenomena by modelling, Proceedings of the 12th International Drying Symposium IDS2000, ISBN 9780444504227, August 2000, Elsevier Science Ltd., Noordwijkerhout, The Netherlands.

Rodal, J.J.A. (1989). Soft-nip calendering of paper and paperboard. Tappi Journal, 72, 5, 177-186. 
Schiel, C. (1969). Optimizing the nip geometry of transversal-flow presses. Pulp and Paper Magazine of Canada, 70, 3, T71-T76.

Skowronski, J. \& Bichard, W. (1987). Fibre-to-fibre bonds in paper. Part I. Measurement of bond strength and specific bond strength. Journal of Pulp and Paper Science, 13, 5, 165-169.

Szikla, Z. (1992). On the Basic Mechanisms of Wet Pressing. PhD thesis, Helsinki University of Technology, Finland.

Szikla, Z. \& Paulapuro, H. (1989a). Changes in z-direction density distributions of paper in wet pressing. Journal of Pulp and Paper Science, 15, 1, J11-J17.

Szikla, Z. \& Paulapuro., H. (1989b). Compression behaviour of fibre mats in wet pressing.In: Fundamentals of Papermaking. In: Transactions of the Ninth Fund. Res. Symp., C. F. Baker and V. W. Punton (Ed.), 587-624, Mechanical Engineering Publications, London, UK.

Terzaghi, K. (1943). Theoretical Soil Mechanics. John Wiley Sons, ISBN 0471853054, New York.

Thoemen, H., (2010). Preface In: Wood-based Panels: An Introduction to Specialists, H. Thoemen, M. Irle \& M. Sernek (Ed.), 123-176, Brunel University Press, ISBN 978-1902316-82-6, London, England.

Thoemen, H. \& Humprey, P.E. (1999). The Continuous pressing process for WBPs: an analytical model. Proceedings of The Third European Panel Products Symposium, pp. 18-30, Llandudno, Wales, UK.

Thoemen, H. \& Humprey, P. (2001). Hot pressing of wood-based composites: selected aspects of the physics investigated by means of a simulation, Proceedings of The Fifth European Panel Products Symposium, pp. 18-30, Llandudno, Wales, UK.

Thoemen, H. \& Humprey, P.E. (2003). Modeling the continuous pressing process for woodbased composites. Wood and Fibre Sci., 35, 456-468.

Thoemen, H. \& Humprey, P.E. (2006). Modeling the physical processes relevant during hot pressing of wood-based composites. Part I. Heat and Mass transfer. Holz RohWerkst., 35, 456-468.

Vomhoff, H. (1998). Dynamic Compressibility of Water-Saturated Fibre Networks and Influence of Local Stress Variations in Wet Pressing. PhD thesis, Royal Institute of Technology, Sweden.

Wahlström, B. (1960). A long term study of water removal and moisture distribution on a newsprint machine press section - Part I. Pulp and Paper Magazine of Canada, 61, 8, T379-T401.

Wahren, D. (1978). Förfarande och anordning för konsolidering och torkning av en fuktig porös bana, Swedish Patent no. 7803672-0.

Wahren, D. (1982). Method and apparatus for the rapid consolidation of moist porous web, USA Patent no. 4,324,613.

Wolcott, M.P.; Kasal, B.; Kamke, F.A. \& Dillard, D.A. (1989). Modeling wood as a polymeric foam: An application to wood-based composite manufacture, Proceedings of the Third Joint ASCE-ASME Mechanics Conference, pp. 53-60, San Diego, LaJolla, CA, July 1989. University of California.

Wood-based Panels International (2010). Particleboard survey part 1, In: Wood-based Panels International, issue 5.

Zombori, B. (2001). Modeling the transient effects during the Hot-Pressing of Wood-based Composites. PhD Thesis, Faculty of the Virginia Polytechnic Institute and State University, Blacksburg, Virginia, USA.

Zombori, B.; Kamke, F.A. \& Watson, L.T. (2002). Simulation of the internal conditions during the hot-pressing process. Wood and Fibre Sci., 35,1, 2-23. 


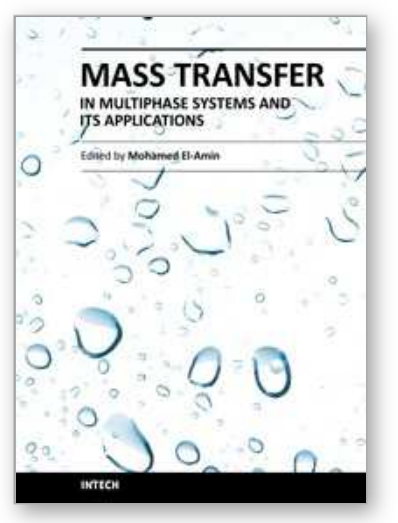

\author{
Mass Transfer in Multiphase Systems and its Applications \\ Edited by Prof. Mohamed El-Amin
}

ISBN 978-953-307-215-9

Hard cover, 780 pages

Publisher InTech

Published online 11, February, 2011

Published in print edition February, 2011

This book covers a number of developing topics in mass transfer processes in multiphase systems for a variety of applications. The book effectively blends theoretical, numerical, modeling and experimental aspects of mass transfer in multiphase systems that are usually encountered in many research areas such as chemical, reactor, environmental and petroleum engineering. From biological and chemical reactors to paper and wood industry and all the way to thin film, the 31 chapters of this book serve as an important reference for any researcher or engineer working in the field of mass transfer and related topics.

\title{
How to reference
}

In order to correctly reference this scholarly work, feel free to copy and paste the following:

Helena Aguilar Ribeiro, Luisa Carvalho, Jorge Martins and Carlos Costa (2011). Transport Phenomena in Paper and Wood-Based Panels Production, Mass Transfer in Multiphase Systems and its Applications, Prof. Mohamed El-Amin (Ed.), ISBN: 978-953-307-215-9, InTech, Available from:

http://www.intechopen.com/books/mass-transfer-in-multiphase-systems-and-its-applications/transportphenomena-in-paper-and-wood-based-panels-production

\section{INTECH}

open science | open minds

\section{InTech Europe}

University Campus STeP Ri Slavka Krautzeka 83/A 51000 Rijeka, Croatia Phone: +385 (51) 770447

Fax: +385 (51) 686166 www.intechopen.com

\section{InTech China}

Unit 405, Office Block, Hotel Equatorial Shanghai No.65, Yan An Road (West), Shanghai, 200040, China 中国上海市延安西路65号上海国际贵都大饭店办公楼405单元 Phone: +86-21-62489820

Fax: +86-21-62489821 
(C) 2011 The Author(s). Licensee IntechOpen. This chapter is distributed under the terms of the Creative Commons Attribution-NonCommercialShareAlike-3.0 License, which permits use, distribution and reproduction for non-commercial purposes, provided the original is properly cited and derivative works building on this content are distributed under the same license. 